\title{
A new light
}

\section{Government investment in photonics seems to be paying dividends in South Africa, which has ambitions to become a major global player in the field.}

When it comes to identifying rapidly emerging regions of photonics research, China is often the first country that people point to, and without doubt its level of investment in photonics and research output are soaring. However, what many don't realize is that thousands of miles away, a quiet transformation is taking place in South Africa.

Over the past five years, the South African government's Department of Science and Technology (DST) has recognized that photonics has strategic importance for the country's future wealth and socio-economic development, and has invested significantly in the area.

The effects, as described in detail in this month's Commentary ${ }^{1}$ on page 673 , can now be clearly seen and have been dramatic. They include the creation of a national research centre and university chairs that are dedicated to both basic and applied laser science and the development of a national strategy for photonics. This strategy, named the Photonics Initiative of South Africa (PISA), is expected to result in funding of several tens of millions of dollars for photonics research in South Africa over the next few years. Its main goals are to stimulate photonics R\&D in both academia and industry and to help drive commercialization and adoption of photonics technology by domestic firms.

At the heart of many of the plans is the country's National Laser Centre (NLC), which was formed in 2000 and marks the origins of the country's investment in photonics. It is now part of the Council for Scientific and Industrial Research (CSIR) and is located at the CSIR's main campus in Pretoria, which features over 50 buildings housing research spanning from the biological sciences and the environment through to metrology, space technology and defence.

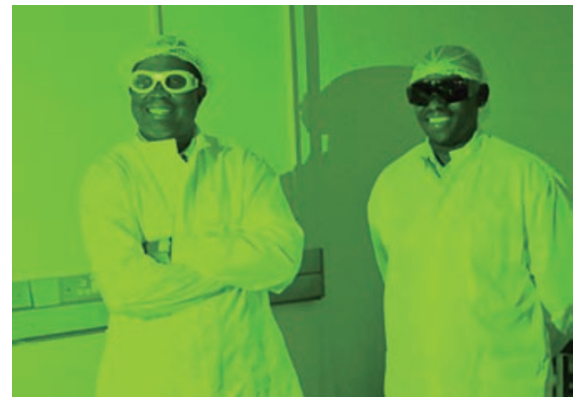

Today, the NLC itself boasts a staff of almost 70 and an annual research budget of around \$6 million, making it the largest photonics research centre in Africa. It carries out research ranging from the development of solid-state laser systems through to environmental sensing, biophotonics and materials processing. As well as conducting its own research, the NLC also runs a rental pool programme for photonics equipment so that the country's universities can access instrumentation that they could not otherwise afford. This has resulted in a significant rise in the number of research papers being published in the optical sciences.

\section{A quiet transformation is taking place in South Africa}

However, the NLC is not the only institution active in photonics research in South Africa, and many university groups across the country are thriving. Perhaps quite aptly given its history and reputation, one area where South Africa looks set to make its mark is in research investigating the optical properties of diamond and diamond-based devices. The academic community recently received a big boost when the DST funded four new research chairs in photonics, covering ultrafast and ultraintense laser science, quantum information processing and communication, nanophotonics, and photonics related to medicine and biology. The positions described above were awarded to leading scientists at the University of Stellenbosch, the University of KwaZulu-Natal in Durban, Rhodes University in Grahamston and the Nelson Mandela Metropolitan University in Port Elizabeth, respectively.

Although the rest of Africa may not be at such an advanced level in terms of its research, the recent creation of a continental network called the African Laser Centre ${ }^{2}$ is starting to benefit other African countries that cannot afford to invest heavily in photonics equipment. Now featuring membership of more than 20 institutions from across the continent including those from Zimbabwe, Tunisia, Algeria, Senegal, Cameroon, Kenya and Ghana, the African Laser Centre aims to help Africa become globally competitive by pooling its resources and encouraging collaboration through conferences and workshops. Only time will tell if it is a success.

The hope is that the combination of these measures will help put Africa, and in particular South Africa, firmly on the global photonics map and help drive the country's socio-economic development. Perhaps the biggest challenges that lie ahead will in fact be commercial rather than scientific. In particular, tricky problems that still need to be overcome are how to persuade industry to embrace photonics technology and how to foster the development of a domestic infrastructure of local suppliers to support its needs.

\footnotetext{
References

1. Bollig, C., Forbes, A. \& Dlamini, T. Nature Photon. 1, 673-675 (2007).

2. African Laser Centre <www.africanlasercentre.org/default.asp>.
} 